\title{
Position Statement of the European Specialist Nurses Organisation (ESNO) in specialist nursing as advanced practice nursing towards 2030
}

\section{Małgorzata Knap ${ }^{1,3} \odot$, Dorota Ozga ${ }^{2,3} \oplus$, Sabina Krupa ${ }^{2,3} \oplus$, Beata Penar-Zadarko ${ }^{2,3} \oplus^{\circ}$, Wioletta Mędrzycka-Dąbrowska ${ }^{3,4} \oplus^{\circ}$, Paweł Witt ${ }^{3,5}$ ๑, Adriano Friganovic ${ }^{6,7}$ (])}

\author{
${ }^{1}$ Collegium Medicum - Institute of Medical Sciences, Jan Kochanowski University in Kielce \\ ${ }^{2}$ Institute of Health Sciences, College of Medical Sciences of the University of Rzeszow, Poland, Rzeszow, Poland \\ ${ }^{3}$ Polish Association of Anaesthesiology and Intensive Care Nurses, Poznań, Poland \\ ${ }^{4}$ Medical University in Gdańsk, Department of Anaesthesiology Nursing and Intensive Care, Gdańsk, Poland \\ 5 Independent Public Children's Clinical Hospital in Warsaw, Department of Anaesthesiology and Intensive Therapy, \\ Department of Anaesthesiology, Intensive Therapy and Post-operative care, Warsaw, Poland \\ University of Applied Health Sciences, Zagreb, Croatia \\ ${ }^{7}$ University Hospital Centre Zagreb, Department of Anesthesiology and Intensive Medicine, Zagreb, Croatia \\ AUTOR DO KORESPONDENCJI/CORRESPONDING AUTHOR: \\ Dorota 0zga \\ Institute of Health Sciences \\ College of Medical Sciences of the University of Rzeszow \\ St. Warzywna 1A, 35-310 Rzeszow, Poland \\ e-mail: gdozga@poczta.fm
}

STRESZCZENIE

Słowa kluczowe:

ABSTRACT

Key words:
STANOWISKO EUROPEJSKIEGO TOWARZYSTWA SPECJALISTÓW PIELĘGNIARSTWA W ZAKRESIE PIELĘGNIARSTWA

\section{SPECJALISTYCZNEGO JAKO PIELEGNIARSTWA ZAAWANSOWANEJ PRAKTYKI DO ROKU 2030}

Wprowadzenie. Pielęgniarstwo polskie przechodząc transformację, powinno obierać wspólne kierunki rozwoju oparte o dorobek profesjonalistów zrzeszonych w międzynarodowym stowarzyszeniu pielęgniarstwa specjalistycznego w Europie. Zmiana systemu kształcenia pielęgniarek w Polsce dała szansę na rozwój oparty na stabilnych ramach programowych.

Podsumowanie. Kształcenie pielęgniarek na poziomie studiów pierwszego i drugiego stopnia to milowy krok w kierunku podwyższenia rangi tego zawodu w Polsce. Dało możliwość prężnego rozwoju profesji, a jednocześnie stało się fundamentem dla badań naukowych. Dziś w obszarze pielęgniarstwa rozwijają się prężne zespoły badawcze zarówno na Uniwersytetach jak i uczelniach wyższych oraz pielęgniarskich towarzystwach naukowych.

zaawansowana praktyka pielęgniarska, Europejskie Towarzystwo Pielęgniarek Specjalistek (ESNO), nauczanie pielęgniarek

\section{POSITION STATEMENT OF THE EUROPEAN SPECIALIST NURSES ORGANISATION (ESNO) IN SPECIALIST NURSING}

\section{AS ADVANCED PRACIICE NURSING IOWARDS 2030}

Introduction. The nursing profession in Poland is subject to continuous transformations, but it should follow the directions based on the common framework for the development of specialist nursing, drawn up by international specialist nurses associations in Europe. A change in the nursing education system in Poland has provided an opportunity for progress based on consistent framework. Summary. Nurse education organised in a system of first cycle and second cycle university courses was a milestone towards improving the status of the nursing profession. The improved position of Polish nurses paved the way for further advancements in this profession and in the related scientific research, which in the past was rarely conducted by Polish nurses; today more and more research teams are launched and operate both at universities and in nurses' scientific associations.

advanced practice nursing, European Specialist Nurses Organisation (ESNO), nurse education 


\section{WPROWADZENIE}

Rozwój badań naukowych w pielęgniarstwie stanowi ustawiczną drogę dochodzenia do nowoczesnego pielęgniarstwa opartego na filozofii jak i etyce, ale podążającego za duchem czasów XXI wieku. Naukowcy w pielęgniarstwie w szerokim zakresie angażują się w planowanie i realizację badań, co skutkuje nie tylko korzyściami dla profesji, lecz w znaczącym stopniu przyczynia się do poprawy całego systemu ochrony zdrowia, w którym pielęgniarki mają swój znaczący udział. Zawsze należy promować wzorzec oparty o pryzmat kapitału zdrowia, który w wymierny sposób powinien być głównym celem funkcjonowania polskiego systemu ochrony zdrowia. Polskie pielęgniarstwo powinno w obszarze przygotowania zawodowego studentów umożliwiać młodym przyszłym pielęgniarkom budować motywację potrzebną do bycia młodym liderem pielęgniarstwa. Przygotowanie zawodowe na kierunku Pielęgniarstwo, musi ugruntować w młodzieży umiejętności wpływania na politykę zdrowotną. Mając na uwadze wzorce Europejskie i Światowe, polskie pielęgniarki muszą implementować elementy tamtej polityki zdrowotnej na płaszczyznę polskiego pielęgniarstwa. Pielęgniarstwo musi podołać zapotrzebowaniu społeczeństwa na opiekę specjalistyczną, której rozwój jest związany z niekorzystnymi wskaźnikami chorobowości w zakresie przewlekłych chorób niezakaźnych zarówno w Europie jak i w Polsce. Aby to było możliwe adepci pielęgniarstwa muszą rozumieć i podejmować trud realizacji holistycznej opieki specjalistycznej wobec człowieka cierpiącego w warunkach najlepszych dla pacjenta i najbardziej ekonomicznych w systemie opieki zdrowotnej tj. w jego środowisku domowym. Tak więc specjalista pielęgniarstwa, staje się świadczeniodawcą dla potrzebujących opieki specjalistycznej, gdzie holistyczna opieka $\mathrm{w}$ domu pacjenta jest tym co zaczyna być standardem opieki w XXI wieku, opartym na zaawansowanej praktyce pielęgniarskiej. Bardzo ważną częścią polskiego pielegniarstwa specjalistycznego jest ustawiczne wspieranie liderów w opracowywaniu pomysłów inicjatyw zdrowotnych we współpracy z międzynarodowymi organizacjami kształtującymi politykę zdrowotną. Uczestnicząc w takich wydarzeniach polskie pielęgniarstwo powinno rozwijać kontakty na płaszczyźnie globalnego zdrowia. Promocja zdrowia i edukacja zdrowotna są bardzo ważnym elementem ochrony zdrowia, w której fundamentalną rolę w edukacji terapeutycznej pacjentów z chorobami przewlekłymi odgrywają pielęgniarki opieki specjalistycznej. Należy zauważyć, że nie ma lepszego miejsca do realizacji promocji zdrowia jak dom pacjenta, gdzie odbiorcą wiedzy jest również jego rodzina.

Kształcenie ustawiczne stanowi fundament rozwoju kompetencji specjalistycznych w pielegniarstwie, jest oparte na aktualnej wiedzy medycznej oraz na faktach naukowych w danej specjalności. Specjalistyczna wiedza pielęgniarska oparta na dowodach naukowych staje się współcześnie także wiarygodnym kierunkiem zmian w praktyce zawodowej, z wynikami opieki poprawiającej jakość życia pacjentów. Belowska J i wsp.[1] stwierdzają, iż w badanej grupie pielęgniarek przystępujących do pań- stwowego egzaminu specjalizacyjnego, wykształcenie ma wpływ na poziom wiedzy, postawy i umiejętności pielęgniarek w zakresie zastosowania Evidence-Based Practice (EBP) w praktyce zawodowej. Niewystarczająca znajomość zagadnień związanych z wykorzystywaniem dowodów naukowych w codziennej praktyce klinicznej pielęgniarek $\mathrm{z}$ wykształceniem średnim może wynikać z ówczesnego systemu kształcenia zawodowego pielęgniarek w Polsce, który obowiązywał przed wejściem Polski do Unii Europejskiej. Bez względu na poziom wykształcenia, istnieje w badanej grupie konieczność stałego, ustawicznego aktualizowania wiedzy z zakresu EBP $[1,2]$.

Medycyna naprawcza nastawiona na jak największą ilość procedur medycznych bez monitorowania odległych efektów terapeutycznych, nie przynosi wymiernej poprawy stanu zdrowia społeczeństwa. W wielu dostępnych publikacjach podkreśla się bardzo ważny element EBP, które wykorzystują naukowcy w pielęgniarstwie, podkreślając aktywne włączenie chorego w proces decydowania, ponieważ to pacjenci zwłaszcza $\mathrm{z}$ chorobami przewlekłymi są najbardziej zainteresowani wynikiem końcowym stosowanych procedur. Założeniem praktyki opartej na EBP jest prawo chorego do informacji i możliwość odrzucenia nieakceptowanej formy leczenia czy innego postępowania i wyboru preferowanej metody. Na koniec warto podkreślić, że bardzo pozytywnym sygnałem jest fakt, że w piśmiennictwie odnaleziono problematykę Evidence-Based Medicine (EBM) i EBP w promocji zdrowia. Artykuł ten podejmuje bardzo ważny problem różnicy w zdefiniowaniu „dowodu naukowego" w medycynie i zdrowiu publicznym. Autorzy publikacji podkreślają niezwykle ważną rolę, jaką dla rozwoju promocji zdrowia opartej na dowodach odegrała medycyna, a jednocześnie wskazując na konieczność znaczącego zmodyfikowania medycznego postrzegania dowodu dla potrzeb szeroko pojętego zdrowia publicznego, $w$ tym promocji zdrowia [3].

Belowska i wsp. [1] wskazują, że wśród pielęgniarek $\mathrm{w}$ badanej grupie przystępującej do specjalizacyjnego egzaminu państwowego, staż pracy w zawodzie nie miał wpływu na poziom wiedzy i postawy związane $z$ Evidence-Based Nursing Practice (EBNP). Bez względu na staż pracy pielęgniarek podkreślają konieczność stałego, ustawicznego aktualizowania wiedzy z zakresu EBNP, m.in. przez uczestnictwo w różnych formach kształcenia podyplomowego. Rola specjalisty pielęgniarstwa anestezjologicznego i intensywnej opieki w obszarze nadzoru okołooperacyjnego jak i intensywnej terapii, jest gwarantem bezpieczeństwa chorych poddawanych różnym interwencjom zabiegowym w bloku operacyjnym jak i intensywnej terapii. Wiedza oraz umiejętności specjalistyczne w tej dziedzinie pielęgniarstwa, zdobywane $\mathrm{w}$ trakcie kształcenia podyplomowego, stawiają specjalistę pielęgniarstwa na bardzo wysokim poziomie w realizacji specjalistycznych świadczeń medycznych.

Należy zwrócić szczególną uwagę na proces kształcenia pielęgniarek z uwzględnieniem między innymi mentoringu, który jak podają autorzy stanowi jeden z siedmiu głównych kompetencji określonych przez European Specialist Nurses Organization (ESNO). Należy zintensyfikować działania zmierzające do poprawy całego systemu pielęgniarstwa 
w Polsce. Utrzymujący się brak liderów w pielęgniarstwie specjalistycznym nie wyzwoli potrzebnych zmian naprawczych systemu podyplomowego kształcenia zawodowego, co tym samym stanowi o stanie pielęgniarstwa w Polsce. Należy przychylić się do stwierdzenia Brene Brown, że przywódcą jest każdy, kto podejmuje się szukać potencjału w innych ludziach i w procesach- i kto ma odwage ten potencjał rozwijać.

\section{PODSUMOWANIE}

Kto jest nam potrzebny do rozwoju pielęgniarstwa zaawansowanej praktyki w Polsce? Potrzebujemy odważnych liderów budujących zespoły profesjonalistów, wykorzystujących doświadczenie zawodowe i dostępne dowody naukowe utrwalające wymierny etos pracy a za tym idącą kulturę danej instytucji. Od liderów oczekujemy krytycznego myślenia, zdolności analizowania i syntetyzowania informacji. Przez profesjonalizm, budowanie zaufania i stania na straży filozofii systemu kształcenia mamy szansę rozwoju pielęgniarstwa jako dyscypliny naukowej. Koniecznym dla rozwoju jest motywowanie do innowacji i wdrażanie ich w obszar specjalistycznej praktyki pielęgniarskiej. Drogą poszukiwania wspólnych płaszczyzn w coraz silniej polaryzujących się poglądach politycznych jest podejmowanie trafnych decyzji ze szczególnym naciskiem na rozwój sztucznej inteligencji i nowoczesnych technologii uczenia się. Obszar nauk medycznych nigdy nie może zostać pozbawiony ich filozoficznych, moralnych i etycznych filarów, a na pewno należy kłaść znaczący nacisk dla wzmocnienia empatii, szacunku i zrozumienia dla drugiego człowieka. Nieodzownym jest zachęcanie do tworzenia innowacji i wdrażanie ich w specjalistyczną praktykę pielęgniarską. Drogą poszukiwania wspólnych płaszczyzn w coraz silniej polaryzujących się poglądach politycznych jest podejmowanie trafnych decyzji ze szczególnym naciskiem na rozwój sztucznej inteligencji i nowoczesnych technologii uczenia się. Obszar nauk medycznych nigdy nie może zostać pozbawiony ich filozoficznych, moralnych i etycznych filarów, a na pewno należy kłaść znaczący nacisk dla wzmocnienia empatii, szacunku i zrozumienia dla drugiego człowieka.

Polskie Towarzystwo Pielęgniarstwa Anestezjologicznego i Intensywnej Opieki oraz Grupa Robocza ds. praktyki w pielęgniarstwie anestezjologicznym i intensywnej opieki, przy PTPAiIO. powołuje zespoły eksperckie ds. opieki zdrowotnej, świadczonej przez specjalistów pielęgniarstwa anestezjologicznego i intensywnej opieki. Zespoły eksperckie pracują nad zaleceniami i rekomendacjami dla profesji. Organizacja działając ustawicznie na rzecz rozwoju zawodowego pielęgniarstwa anestezjologicznego i intensywnej opieki, wymiernie kreuje profesjonalizm zawodowy.

\section{Stanowisko ESNO z 26 kwietnia 2019 r.}

\section{Stanowisko "Pielęgniarki specjalistki w europejskiej opiece zdrowotnej w perspektywie do roku 2030"}

\section{Obecny stan opieki zdrowotnej i sytuacja pielęgniarek specjalistek}

Rozwój roli pielęgniarek specjalistek w Europie jeszcze nigdy nie miał takiego znaczenia. W ESNO definiujemy pojęcie "pielęgniarki specjalistki”, obejmując nim również inne tytuły, takie jak pielęgniarka dyplomowana w zakresie zaawansowanej praktyki pielęgniarskiej (Advance Nurse Practitioner), pielęgniarka dyplomowana w zakresie praktyki pielęgniarskiej (Nurse Practitioner) i inne określenia odnoszące do pielęgniarek z wykształceniem policencjackim lub akademickim oraz pielęgniarki posiadające duże doświadczenie w określonej dziedzinie zdrowia.

Zawód ten służy obywatelom Europy, zapewniając najwyższy poziom opieki w szpitalach, placówkach opiekuńczych, a przede wszystkim w szeroko rozumianym środowisku pacjentów. Sto lat temu, gdy opieka instytucjonalna dopiero się rozwijała, pielęgniarki odgrywały czołową rolę w zapewnianiu opieki chorym i potrzebującym. Jednak w ostatnich dekadach odpowiedzialność w opiece zdrowotnej w dużym stopniu przesunęła się na lekarzy, przyczyniając się do znacznej instrumentalizacji opieki $\mathrm{z}$ wykorzystaniem medycyny naprawczej. Obecnie obserwujemy transformację opieki zdrowotnej w kierunku bardziej integracyjnego i interdyscyplinarnego podejścia, które doprowadziło do objęcia przez pielęgniarki jednej z czołowych funkcji w wielu sytuacjach klinicznych ze względu na prezentowany przez nie wysoki poziom kompetencji i wiedzy.

W dzisiejszej opiece zdrowotnej obserwujemy rosnące oczekiwania obywateli Europy co do efektów leczenia. Ich wyraz stanowią dyrektywy w sprawie transgranicznego dostępu do opieki zdrowotnej (w sprawie stosowania praw pacjentów w transgranicznej opiece zdrowotnej) oraz zastosowania powszechnego ubezpieczenia zdrowotnego, a także wnioski z unijnego szczytu zdrowia (EU Health Summit) - "Wspólna wizja przyszłości opieki zdrowotnej w Europie - wyznaczenie kierunku na rok 2019 i lata kolejne”. Stanowi to odzwierciedlenie rosnących wyzwań, jakim pielęgniarki specjalistki będą musiały sprostać. 


\section{Rozwój zawodu pielęgniarki specjalistki}

Zawód pielęgniarki specjalistki rozwijał się przez lata, bazując na podejściu do pacjenta z perspektywy stałego rozwoju edukacyjnego, który umożliwia zapewnienie najlepszej możliwej opieki. W rezultacie pielęgniarki specjalistki stały się zdolne do zapewnienia standardów koniecznych w takich dziedzinach specjalizacji jak intensywna opieka, diabetologia, reumatologia, onkologia, transplantologia, nefrologia i wiele innych.

Od pielęgniarek specjalistek oczekuje się obecnie realizacji obowiązków w sposób niezależny i zapewniania opieki przy zachowaniu pełnej odpowiedzialności za jej poziom zgodnie z przejrzystymi ramami regulacyjnymi. Działalność pielęgniarek specjalistek obejmuje również istotne zagrożenia zdrowotne, takie jak oporność na szczepionki i środki przeciwdrobnoustrojowe. Oprócz tego przedstawicielki tego zawodu w swojej pracy zmagają się z problemami związanymi ze starzeniem się społeczeństwa i jednoczesnym wzrostem występowania chorób współistniejących i terapią wielolekową. Wiąże się to ze zwiększonymi oczekiwaniami co do wiedzy specjalistycznej pielęgniarek.

Cechą unikatową zawodu pielęgniarki jest bliska relacja z pacjentami, dzięki czemu mają one niezwykłą możliwość wglądu w proces leczenia i jego ulepszania. Pielęgniarki specjalistki mogą więc $\mathrm{w}$ istotnym stopniu przyczyniać się do poprawy jakości efektów leczenia i ich lepszego wykorzystania, znacznie przyczyniając się do praktyki opartej na dowodach naukowych. Wśród wiedzy specjalistycznej należy również wymienić wiedzę z zakresu chorób zakaźnych, zdrowia psychicznego, opieki skoncentrowanej na pacjencie, grup znajdujących się w niekorzystnym położeniu oraz przejście między opieką podstawową, specjalistyczną a wysoce specjalistyczną.

Stojącym przed pielęgniarkami specjalistkami wyzwaniem na drodze ciągłego rozwoju jest uświadomienie sobie korzyści związanych z odejściem od medycznego modelu świadczenia opieki w kierunku holistycznego podejścia do pielęgniarstwa w celu osiągnięcia jak najlepszych efektów leczenia. Należy tutaj przytoczyć niedawne oświadczenie Organizacji Współpracy Gospodarczej i Rozwoju (OECD) w sprawie ewoluujących ról pielęgniarek specjalistek: Wiele krajów przeprowadziło $\mathrm{w}$ ostatniej dekadzie reformy wprowadzające zaawansowane stanowiska pielęgniarskie w podstawowej opiece zdrowotnej w celu poprawy dostępu do opieki, podniesienia jej jakości oraz ograniczenia kosztów. Niniejszy dokument roboczy zawiera analizę zmian we wspomnianych rolach pielęgniarek w 37 krajach OECD i UE.

Wyróżniono cztery główne trendy:

1) powstanie w kilku krajach określonych zaawansowanych stanowisk pielęgniarskich stanowiących połączenie tradycyjnego zawodu pielęgniarki i lekarza; 2) wprowadzenie różnych nowych, dodatkowych stanowisk w zawodzie pielęgniarki, często związanych z leczeniem schorzeń przewlekłych;3) zwiększenie liczby programów edukacyjnych kształcących pielęgniarki w zakresie wymaganych umiejętności i kompetencji, oraz 4) od 2010 r. przyjęcie nowych przepisów w wielu krajach umożliwiających niektórym pielęgniarkom przepisywanie leków (m.in. w Estonii, Finlandii, Francji, Holandii, Polsce i Hiszpanii).

\section{Obecny kontekst zawodu pielęgniarki specjalistki}

Zawód pielęgniarki specjalistki można określić za pomocą siedmiu głównych kompetencji na podstawie CTF ESNO: role w praktyce klinicznej, relacje z pacjentem, nauczanie i szkolenie pacjentów, mentoring, badania, organizacja i zarządzanie, etyka i podejmowanie decyzji, przywództwo i tworzenie polityki, profilaktyka. $\mathrm{W}$ tym procesie ewolucji obserwowanym w Europie i na świecie dostrzegliśmy, że różne przyjmowane definicje można podsumować jednym głównym stwierdzeniem: jakość opieki zdrowotnej osiągana dzięki gruntownie wykształconemu personelowi zgodnie z uznanymi europejskimi standardami edukacji. Wspomniane definicje przytoczono poniżej:

Definicja Royal College of Nurses (RCN): Zaawansowana praktyka to poziom praktyki, a nie jej rodzaj. Pieleggniarka dyplomowana w zakresie zaawansowanej praktyki pielęgniarskiej (Advanced Nurse Practitioner) posiada stopień magistra w zakresie praktyki klinicznej i została uznana za biegłą w stosowaniu specjalistycznej wiedzy i umiejętności klinicznych. Ma ona swobodę i uprawnienia do działania, podejmowania samodzielnych decyzji przy ocenie, diagnozowaniu i leczeniu pacjentów. "Standardy zaawansowanej praktyki, standardy RCN w zakresie praktyki pielęgniarskiej na zaawansowanym poziomie".

Definicja ESNO: Stosuje się tytuł pielęgniarki specjalistki oraz inne tytuły, takie jak pielęgniarka dyplomowana w zakresie zaawansowanej praktyki pielęgniarskiej, pielęgniarka dyplomowana w zakresie praktyki pielęgniarskiej i inne określenia odnoszące do pielęgniarek $\mathrm{z}$ wykształceniem policencjackim lub akademickim oraz pielęgniarki posiadające duże doświadczenie w określonej dziedzinie zdrowia.

Definicja Międzynarodowej Rady Pielegniarek (ICN): Pielęgniarka dyplomowana w zakresie (zaawansowanej) praktyki pielęgniarskiej jest pielęgniarką dyplomowaną, która posiada bazę w postaci wiedzy specjalistycznej, złożone umiejętności podejmowania decyzji i kompetencje kliniczne umożliwiające szerszy zakres praktyki, która kształtuje się zależnie od kontekstu i/lub kraju. Do podjęcia pracy na stanowisku podstawowym zalecany jest stopień magistra.

Pozycja lekarzy w Europie jest dobrze ugruntowana i uznana, w przeciwieństwie do wiedzy specjalistycznej i roli pielęgniarek specjalistek. W ostatnich dekadach nastąpily istotne zmiany w zawodzie pielęgniarek specjalistek prowadzące do powstania specjalizacji uznawanych za zaawansowane i praktyki na wysokim poziomie akademickim. Oczekuje się również przyrostu liczby osób z wykształceniem wyższym - do 2030 r. 30-40\% pielęgniarek będzie miało stopieńmagistra. Standardy te nie są jednak zharmonizowane. Na przykład stanowisko pielęgniarki specjalistki jest prawnie uznane przez organy rejestracyjne w niektórych krajach UE, jednak nie jest ono powszechnie stosowane we wszystkich obszarach Europy. Często kwestia ta nie jest uregulowana na szczeblu krajowym lub brak jest stosownych przepisów krajowych. Dlatego występuje prawdziwa potrzeba ujednolicenia tej kwestii w Europie. Celem jest stworzenie ogólnego 
planu wdrożenia solidnych ram umożliwiających uznanie zawodu pielęgniarek specjalistek w Europie. Pozwoli to na spełnienie wymogów w zakresie zapewnienia jakości opieki pielęgniarskiej, budowania zdolności, mobilności i radzenie sobie z problemem braków personelu pielegniarskiego. Sprawa ta wymaga rozwiązania, aby sprostać potrzebom pacjentów, co prowadzi do bezpieczniejszej opieki nad pacjentem i korzyści ekonomicznych w czasach, gdy budżety systemów opieki zdrowotnej podlegają rygorystycznym cięciom.

\section{Zalecenia w zakresie uznania zawodu pielęgniarki specjalistki w Europie}

Europejska Organizacja Pielegniarek Specjalistek (ESNO) wzywa organy krajowe do wsparcia dla utworzenia grupy roboczej ds. opieki zdrowotnej świadczonej przez pielęgniarki specjalistki i wdrożenia transgranicznych ram regulacyjnych w celu ugruntowania prawnego i zharmonizowania pozycji pielęgniarek specjalistycznych w każdym z państw członkowskich UE. Wzywamy do uznania na skalę europejską tytułu pielęgniarki specjalistki z jasno określonymi obowiązkami zharmonizowanymi zgodnie z wyznaczonym standardem. Można to osiągnąć dzięki programom edukacyjnym i szkoleniowym na zaawansowanym poziomie uznanym na skalę europejską, do których należy m.in. ustawiczny akredytowany program ustawicznego rozwoju zawodowego (CPD) oraz korzystając z opracowanych przez ESNO wspólnych ram szkoleniowych "Kompetencja pielęgniarek specjalistek: wspólne podstawy kompetencji do wspólnych ram szkolenia w każdej ze specjalności”.

ESNO zdecydowanie uważa, że to podejście niewątpliwie przyniesie pozytywne skutki i pozwoli na utrzymanie stabilnego i dysponującego odpowiednim przygotowaniem personelu pielęgniarskiego o ustanowionej pozycji. Będzie to oznaczać, że istotna rola pielęgniarek specjalistek może zyskać prawdziwe uznanie i zajmować jedną z czołowych pozycji w opiece zdrowotnej, która pozwoli na dostosowanie się do zmieniających się potrzeb teraz i w przyszłości. Pozwoli to na świadczenie opieki nad pacjentami na najwyższym poziomie i przyczyni się do rozwoju praktyki opartej na dowodach naukowych, niosąc korzyści ekonomiczne i zdrowotne dla społeczeństwa.

Bruksela, 26 kwietnia 2019 r.

Position Statement "The Specialist Nurses in European Healthcare Towards 2030"

Eng. Supplementary material 1.

Thumaczenie stanowiska na jezzyk polski za zgoda The European Specialist Nurses Organisation (ESNO) z dnia 10 lipca 2019 roku.

\section{Position Statement}

\section{"The Specialist Nurses in European Healthcare Towards 2030"}

\section{Todays landscape of health and Specialist Nurses}

Never before has a profession in Europe ${ }^{1}$ been as important as the evolution of the role of the Specialist Nurses ${ }^{2}$. In ESNO we define the title 'Specialist Nurse' by including the other titles such as Advance Nurse Practitioner, Nurse Practitioner or otherwise referring to nurses with post bachelor or academic education background and nurses highly experienced in a certain health discipline.

This professional role serves the European citizen with the highest standard of care in hospitals, care institutions but above all everywhere in the community. A century ago, in the early developments of institutional health settings, nurses played a leading role in delivering healthcare to the sick and needy. However, over the past decades the responsibility of health was placed more and more in the hands of doctors, and so has become highly medicalised. Today, we are now seeing a transformation of healthcare towards a more inclusive and interdisciplinary approach which has led to the nurse having a leading role in many clinical situations due their high levels of competency and knowledge.

Tin health setting today we see a growing expectation of clinical outcomes by the European citizen. This follows the Directives on the Cross Border Access for Health ${ }^{3}$ and the adoption of the Universal Health Coverage (UHC), and the outcome of the EU Health Summit - A SHARED VISION FOR THE FUTURE OF HEALTH IN EUROPE Paving the way in 2019 and beyond ${ }^{5}$. This reflects the growing spectrum of challenges that the specialist nurses will encounter and be expected to deliver.

2-C. Dury, C. Hall, FHEA, JL. Danan, J. Mondoux, M.C. Aguiar Barbieri-Figueiredo, M.A.M. Costa, C.Debout (2014) Specialist nurse in Europe: education, regulation and rôle, International nursing Review

${ }^{3}$ https://eur-lex.europa.eu/legal-content/EN/TXT/PDF/?uri=CELEX:32011L0024\&from=EN

${ }^{4}$ https://www.who.int/news-room/fact-sheets/detail/universal-health-coverage-(uhc)

${ }^{5}$ https://www.euhealthsummit.eu/wp-content/uploads/Future-of-Health-recommendations-in-full-new.pdf 


\section{Evolution of the profession of Specialist Nurses}

The Specialist Nurse's profession has developed over the years and is based on general and fundamentals of treating patients from a standpoint of progressive educational development which enables the best possible care to be delivered. This has resulted in the Specialist Nurses profession being capable of providing the necessary standards to address such specialist areas as Intensive Care, Diabetes, Rheumatology, Oncology, Transplant, Renal and many other areas.

Specialist Nurses are now expected to perform duties in an independent way and to deliver treatment that they will be wholly accountable for under a clear and transparent regulatory framework.

The field of the Specialist Nurses also covers vital health threats such as Vaccination and Anti-Microbial Resistance (AMR). In addition, this profession is addressing the increasing ageing population with the subsequent increase in comorbidity and polypharmacy. This places increased expectations on their expertise.

A unique feature of the nursing profession is the close relationship that they have with the patients that they serve. This enables the profession to be in the exclusive position understanding the treatment process and how this may be improved. This provides Specialist Nurses with the capability to input in a very meaningful way to improvements in the management and treatment of health outcomes. Thus, adding greatly to evidence-based outcomes. This expertise can of course, be extended to Non-Communicable Diseases (NCD), mental health, patient centred care, vulnerable groups, and transition between primary $y^{6}$, secondary and tertiary healthcare settings.

The challenge for Specialist Nurses in moving forward is to realise the benefits of moving away from a medical model of care provision towards adopting a holistic nursing approach in order to achieve the best patient outcomes. It is important to note a recent statement by the Organisation for Economic Co-operation and Development (OECD) on the evolving roles of the Specialist Nurse:

Many OECD countries have undergone reforms over the past decade to introduce advanced roles for nurses in primary care to improve access to care, quality of care and/or to reduce costs. This working paper provides an analysis of these nurse role developments and reforms in $37 \mathrm{OECD}$ and EU countries. Four main trends emerge: 1) the development in several countries of specific advanced practice nursing roles at the interface between the traditional nursing and medical professions; 2) the introduction of various new, supplementary nursing roles, often focused on the management of chronic conditions; 3 ) the rise in educational programmes to train nurses to the required skills and competencies; and 4) the adoption of new laws and regulations in a number of countries since 2010 to allow certain categories of nurses to prescribe pharmaceuticals (including in Estonia, Finland, France, Netherlands, Poland and Spain).

\section{Today's context of Specialist Nurses}

In this context, the Specialist Nurse's role can be summarised in to seven key competences according ESNO CTF: Clinical roles; Patient Relation; Patient teaching and coaching; Mentoring; Research; Organisation and management; Ethic and decision making; Leadership and Policymaking; Prevention

In this evolution process in Europe and Global we see different definitions are accepted and covered by one main message: quality of health by advanced educated professional and European recognized standards education with the definitions below:

Royal College of Nurses $(R C N)$ definition: Advanced practice is a level of practice, rather than a type of practice. Advanced Nurse Practitioners are educated at Masters Level in clinical practice and have been assessed as competent in practice using their expert clinical knowledge and skills. They have the freedom and authority to act, making autonomous decisions in the assessment, diagnosis and treatment of patients. 'Advanced Practice Standards, RCN standards for advanced level nursing practice ${ }^{7}$.

ESNO definition: The title Specialist Nurse is used and including the other titles such as Advance Nurse Practitioner, Nurse Practitioner or otherwise referring to nurses with post bachelor or academic education background and nurses highly experienced in a certain health discipline.

International Council of Nurses (ICN) definition: A Nurse Practitioner/Advanced Practice Nurse is a registered nurse who has acquired the expert knowledge base, complex decision-making skills and clinical competencies for expanded practice, the characteristics of which are shaped by the context and/or country in which s/he is credentialed to practice. A master's degree is recommended for entry level ${ }^{8}$.

The position and standing of the medical profession (i.e. doctors) is well established and recognised across Europe. This is in direct contrast to the expertise and role of the Specialist Nurse in Europe.

Over the past decades there has been a significant development in the field of the Specialist Nurses resulting in specialisations that are recognised as advanced to a high academic level of practice. There is also an expectancy that there will be an incremental increase in academic attainment, where by $203030-40 \%$ will be educated to Masters level. However these standards are not harmonised. For instance the position of the Specialist Nurse is legally recognised

\footnotetext{
${ }^{6}$ https://www.oecd-ilibrary.org/docserver/a8756593-en.pdf?expires=1555410406\&id=id\&accname=guest\&checksum=40159D9DB D029F9A001390ADF518D559

${ }^{7}$ https://www.rcn.org.uk/professional-development/advanced-practice-standards

${ }^{8} \mathrm{http}$ ://international.aanp.org/practice/apnroles
} 
in certain EU national registration authorities but this is not universal across all of the European areas. In fact, there is often no regulation on a national level or even national regulations in place. Therefore, there is a real need to remove this fragmentation across the Europe. The objective must be to introduce an overall plan to build a robust framework to enable Specialist Nurses to be recognised across Europe. This will support the need to address the requirement for nursing quality assurance, capacity building, mobility ${ }^{9}$ and the alarming increasing on shortage of nurses.

We need to address this so that patient's needs are met, leading to safer patient care and positive economic benefits in a time when healthcare budgets are under great austerity measures.

\section{Recommendation towards European recognition}

The European Specialist Nurses Organization (ESNO) calls on national authorities to invest in a Specialist Nurses Health Workforce and implement cross border Regulatory Frameworks towards a legally embedded and harmonised position of the Specialist Nurses in each Member State. We maintain that a recognised European title for Specialist Nurses with clearly defined and harmonised roles and responsibilities to a prescribed standard is called for. This can easily be achieved through a European recognised advanced level of practice education programmes, including an ongoing accredited Continuing Professional Development programme (CPD) ${ }^{10}$ and using the by ESNO developed Common Training Framework 'Competences of the Specialist Nurse (NS): Common plinth of competences for a Common Training Framework of each specialty'11.

The ESNO strongly believe in this approach which will undoubtedly produce a truly positive outcome and achieve a substantive, stable and established nurses' health-workforce. This will mean that the Specialist Nurses vital role can be truly recognised and so establish a leading position within healthcare that can adapt to the changing needs of healthcare now and in the future. This will deliver patient care to the highest level and contribute to the evolution of evidence-based practice with the subsequent economic and health benefits to society.

Brussels 26-04-2019

\footnotetext{
${ }^{9}$ http://www.euro.who.int/_data/assets/pdf_file/0017/152324/Health-Professional-Mobility-Health-Systems.pdf

${ }^{10} \mathrm{http}$ ://ec.europa.eu/education/ects/users-guide/lifelong-learning-open-learning-opportunities_en.htm

${ }^{11} \mathrm{http} / / /$ www.esno.org/assets/esno-common_training_framework_27-10-2015.pdf
}

\section{ORCID}

Małgorzata Knap (iD) https://orcid.org/0000-0003-0425-7631

Dorota 0zga (iD https://orcid.org/0000-0002-9457-9388

Sabina Krupa (iD https://orcid.org/0000-0002-3002-3153

Beata Penar-Zadarko iD https://orcid.org/0000-0002-3896-1750

Wioletta Mędrzycka-Dąbrowska (iD https://orcid.org/0000-0001-8377-4893

Paweł Witt (iD https://orcid.org/0000-0002-4053-0853

Adriano Friganovic (iD) https://orcid.org/0000-0002-9528-6464

\section{PIŚMIENNICTWO}

1. Belowska J, Panczyk M, Zarzeka A, i wsp. Staż pracy a wiedza i postawy personelu pielęgniarskiego przystępującego do egzaminów specjalizacyjnych, organizowanych przez Centrum Kształcenia Podyplomowego Pielęgniarek i Położnych, wobec Evidence-Based Practice [Work experience and knowledge and attitudes of nurses taking state examinations organized by the Centre of Postgraduate Education for Nurses and Midwives with respect to Evidence-Based Practice]. Pielęgniarstwo Polskie. 2016;3(61): 340-346.

2. Ozga D, Jędrzejczyk-Cwanek M, Woźniak $K$, et al. Knowledge, Behaviors, and Attitudes of Polish Nurses as Compared with Evidence-Based Practice in Relation to the Guidelines of the European Resuscitation Council. Global Advances in Health and Medicine, 2019. https://doi.org/10.1177/2164956119897566

3. Gotlib J, Belowska J, Panczyk M, i wsp. Evidence-Based Medicine and EvidenceBased Nursing Practice - Przegląd Polskiego piśmiennictwa naukowego [EvidenceBased Medicine and Evidence-Based Nursing Practice - a review of the Polish scientific literature]. Problemy Pielęgniarstwa. 2014, 22(2): 223-227.

4. https://www.esno.org/assets/esno_position_statement_april_2019_final.pdf (Accessed 20 March 2020).

5. Brown B. Odwaga w przywództwie. Cztery kompetencje autentycznego lidera [Dare to Lead: Brave Work. Tough Conversations. Whole Hearts]. Wydawnictwo MT Biznes; 2019.

6. Knap M. Ocena poziomu natężenia i terapia bólu -zadanie zawodowe profesjonalnie przygotowanych pielęgniarek [Assessment of pain intensity and therapy - work duties of professional nurses]. Nowe trendy w edukacji i praktyce pracowników ochrony zdrowia. Profesjonalizm kluczem do bezpieczeństwa pacjenta [New trends in education and practice of healthcare workers. Professionalism as a key to patients' safety]. Ostrowiec Świętokrzyski. 2018; 6: 243-255.

Praca zgłoszona do czasopisma: 08.04.2020

Praca zaakceptowana do druku: 12.06.2020 